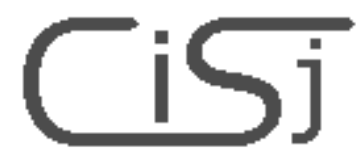

computing@tanet.edu.te.ua www.tanet.edu.te.ua/computing
ISSN 1727-6209

International Scientific Journal of Computing

\title{
РОЗВ’ЯЗУВАННЯ НЕЛІНІЙНО-ПОЛІНОМІАЛЬНИХ РІВНЯНЬ ГІЛЛЯСТИМИ ЛАНЦЮГОВИМИ ДРОБАМИ
}

\section{М.Недашковський}

\author{
(Тернопіль, Академія народного господарства)
}

Резюме: пропонуються нові підходи до розв'язання поліноміально-нелінійних матричних рівнянь за допомогою матричними гіллястих ланщюгових дробів. Для запису розв'язків матричних поліномів пропонуються алгоритми, які дозволяють одержати розвинення шуканих невідомих у так звані фігурні Jдроби, Т-дроби та С-дроби, також періодичні матричні гіллясті дроби канонічного вигляду.

Результати можуть використані у системах комп'ютерної алгебри таких як REDUCE, тиMATH, MATHEMATICA, MAPLE, MatLab, MathCad i DERIVE.

Ключові слова: нелінійні рівняння, матричні ланцююгові дроби.

\section{1. ВСТУП}

Метою даного повідомлення $є$ нові підходи до розв'язання поліноміально-нелінійних рівнянь, котрі $€$ важливим класом нелінійних рівнянь математичної фізики, моделювання в енергетиці, електротехніці. Багато задач фізики ядра, конденсованих середовищ і елементарних часток можуть в принципі бути зведені до розв'язання поліноміально-нелінійних рівнянь.

Зараз для задач чисельного розв'язання одномірних алгебраїчних задач довільної нелінійності розроблено чимало ітераційних методів. Досить добре розвинуті і прямі методи розв'язування скалярних поліноміальних рівнянь.

Ситуація проте суттєво ускладнюється, коли доводиться переходити до нелінійних багатомірних рівнянь. При цьому, якщо не відома досить достовірна апріорна інформація про початкові (пробні) розв'язки, то принципове розв'язання тієї чи іншої нелінійної задачі стає проблематичним. Бухбергер [7] запропонував методи побудови алгоритмів зведення $M$ - мірних поліноміально-нелінійних алгебраїчних рівнянь до трикутної форми, використовуючи базис Гробнера. Не дивлячись на те, що в даний час ці алгоритми $\epsilon$ оптимальними, не можна вважати, що задача розв'язування даного класу систем виконана вичерпно. Адже в дійсності розв'язати систему поліноміально-нелінійних рівнянь - це значить знайти кортежі (тобто впорядкований набір) розв'язків.
В даній роботі мова піде про розв'язання систем поліноміально-нелінійних рівнянь та матричних поліноміальних рівнянь.

Слід зазначити, що мова піде не тільки про чисельні, але і про символьні методи розв'язання. Останнім часом в електротехніці, фізиці та інших областях науки й техніки виник інтерес до використання комп'ютерів також для символьних перетворень i одержання аналітичних розв'язків. Інтерес до таких досліджень значно виріс у зв'язку 3 інтенсивними роботами із штучного інтелекту i по створенню нейрокомп'ютерних систем.

Операції 3 символьними елементами накладають принципово інші вимоги на зовнішні пристрої ЕОМ, алгоритмічні мови програмування, котрі використовуються. На першому плані виходять зовсім інші критерії ефективності та оптимальності. Тому потрібні інші підходи до розв'язання цієї задачі [1].

Відомо немало ефективних методів для обчислення невідомих числових систем алгебраїчних рівнянь [2]. Обчислювальна схема кожного 3 них полягає в застосуванні певних рекурентних співвідношень, послідовне використання яких і дає значення невідомих. Але для аналітичного розв' язання матричних рівнянь iз символьними елементами подібний підхід практично не придатний.

Сьогодні існують i успішно розвиваються декілька напрямків і концепцій для виконання символьних перетворень [3, 4]. Із систем універсального характеру найбільш розповсюдженими $\epsilon$ REDUCE, MAPLE, 
muMATH, MATHEMATICA, DERIVE, MatLab i MathCad. Їх можна використовувати для різних задач комп'ютерної алгебри, в тому числі і для розв'язання систем алгебраїчних рівнянь. Але цей розділ ще не настільки добре розвинутий, як відповідні методи для числових систем. Алгоритми, взяті за основу, досить далекі від оптимальних.

\section{2. ІДЕЯ ПІДХОДУ}

Мова піде про побудову кліткових алгоритмів розв'язання систем алгебраїчних рівнянь матричними гіллястими ланцюговими дробами. Цей підхід цікавий і сам по собі. А крім того ще й створює нову методологію для одержання нових алгоритмі та нових результатів.

Розглянемо композицію

$$
\left\{\begin{array}{l}
S_{0}(w)=s_{0}(w) \\
S_{m}(w)=S_{m-1}\left(s_{k_{1} k_{2} \ldots k_{m}}(w)\right) \quad(\mathrm{m}=1,2, \ldots)
\end{array}\right.
$$

дробово-лінійних перетворень

$$
\left\{\begin{array}{l}
s_{0}(w)=w, \\
s_{k_{1} k_{2} \ldots k_{m}}=\sum_{k_{m}=1}^{N} \frac{a_{k_{1} k_{2} \ldots k_{m}}}{b_{k_{1} k_{2} \ldots k_{m}}+w}
\end{array}\right.
$$

Означення 1. Матричним гіллястим ланцюговим дробом називається композиція $S(w)$ нескінченого числа дробово-лінійних перетворень (2).

Надалі матричний ГЛД будемо записувати у вигляді

$$
D=\sum_{k_{1}=1}^{N} \frac{a_{k_{1}} \mid}{b_{k_{1}}}+\sum_{k_{2}=1}^{N} \frac{a_{k_{1} k_{2}} \mid}{\mid b_{k_{1} k_{2}}}+\ldots+\sum_{k_{i}=1}^{N} \frac{a_{k_{1} k_{2} k_{3} \ldots k_{i}} \mid}{\mid b_{k_{1} k_{2} k_{3} \ldots k_{i}}}+\ldots
$$

Припускається, що $a_{k_{1} k_{2} \ldots k_{s}}$ та $b_{k_{l} k_{2} \ldots k_{s}}$ для всіх $s=1,2,3, \ldots$ - це квадратні, невироджені $p \times p$-матриці.

Означення 2. Скінчений дріб

$$
D_{m}=\sum_{k_{1}=1}^{N} \frac{a_{k_{1}} \mid}{\mid b_{k_{1}}}+\sum_{k_{2}=1}^{N} \frac{a_{k_{1} k_{2}} \mid}{\mid b_{k_{1} k_{2}}}+\ldots+\sum_{k_{m i}=1}^{N} \frac{a_{k_{1} k_{2} k_{3} \ldots k_{m i}} \mid}{\mid b_{k_{1} k_{2} k_{3} \ldots k_{m}}}(4)
$$

називають $m-$ им підхідним дробом нескінченого ГЛД (3).

Після цих попередніх зауважень перейдемо до суті підходу.

\section{Розглянемо рівняння}

$$
x^{n}+a_{1} x^{n-1}+a_{2} x^{n-2}+\ldots+a_{n-1} x+a_{n}=0_{(5)}
$$

Теорема Вієта. Нехай $f(x)$ многочлен степені $n$ із коефіцієнтами із деякого поля i старшим коефіцієнтом 1 . Над полем, котре має всі корені $f(x)$ (наприклад, над полем розкладу для $f(x)$ ), многочлен $f(x)$ розкладається на лінійні множники:

$$
\begin{aligned}
& f(x)=x_{n}+a_{n-1} x^{n-1}+\ldots+a_{1} x+a_{0}= \\
& =\left(x-\alpha_{1}\right)\left(x-\alpha_{2}\right) \ldots\left(x-\alpha_{n 1}\right)
\end{aligned}
$$

де $\alpha_{i}$ - корені $f(x), i=1,2, \ldots, n$. Причому виконуються співвідношення:

$$
\left\{\begin{array}{l}
a_{0}=(-1)^{n} \alpha_{1} \alpha_{2} . . \alpha_{n} \\
a_{1}=(-1)^{n-1}\left(\alpha_{1} \alpha_{2} . . \alpha_{n-1}+\right. \\
\left.+\alpha_{1} \alpha_{2} . . \alpha_{n-2} \alpha_{n}+\ldots+\alpha_{2} \alpha_{3} . . a_{n}\right) \\
a_{n-1}=-\left(\alpha_{1}+\alpha_{2}+\ldots+\alpha_{n}\right)
\end{array}\right.
$$

Твердження 1. Розв'язок рівняння (5) $n$-го порядку можна подати у вигляді нескінченого періодичного гіллястого дробу виду (3) $3 n-1$ вітками розгалуження.

Доведення. На основі теореми Вієта рівняння (5) можна також записати у вигляді

$$
\begin{aligned}
& \left(x-\alpha_{1}\right)\left(x-\alpha_{2}\right) \ldots\left(x-\alpha_{n-1}\right)\left(x-b_{0}\right)+ \\
& +b_{1} x^{n-2}+b_{2} x^{n-3}+\ldots+b_{n-3} x+b_{n-2}=0^{(7)}
\end{aligned}
$$

У припущенні, що $\alpha_{1}, \alpha_{2}, \ldots, \alpha_{n-1}$ не $є$ розв'язками (5) можна записати:

$$
x=b_{0}+\frac{b_{1} x^{n-2}+b_{2} x^{n-3}+\ldots+b_{n-3} x+b_{n-2}}{\left(x-\alpha_{1}\right)\left(x-\alpha_{2}\right) \ldots\left(x-\alpha_{n-1}\right)}
$$

Останнє рівняння може бути також подане у вигляді:

$$
x=b_{0}+\frac{y_{1}}{x-\alpha_{1}}+\frac{y_{2}}{x-\alpha_{2}}+\ldots+\frac{y_{n-1}}{x-\alpha_{n-1}},(9)
$$


де $y_{1}, y_{2}, \ldots$ та $y_{n-1}$ деякі невідомі числа. Для ïх визначення можна скористатися методом невизначених коефіцієнтів. 3 цією метою зведемо прості дроби у (9) до спільного знаменника:

$$
\begin{aligned}
& x=\left[b_{0} \prod_{i=1}^{n-1}\left(x-\alpha_{i}\right)+y_{1} \prod_{i=2}^{n-1}\left(x-\alpha_{i}\right)+\right. \\
& +y_{2}\left(x-\alpha_{1}\right) \prod_{i=3}^{n-1}\left(x-\alpha_{i}\right)+\ldots+ \\
& +y_{j} \prod_{i=1}^{j-1}\left(x-\alpha_{i}\right) \prod_{i=j+1}^{n-1}\left(x-\alpha_{i}\right)+ \\
& \left.+\ldots+y_{n-1} \prod_{i=1}^{n-2}\left(x-\alpha_{i}\right)\right] / \prod_{i=1}^{n-2}\left(x-\alpha_{i}\right)
\end{aligned}
$$

Звідки одержуємо рівняння

$$
\begin{aligned}
& -x \prod_{i=1}^{n-1}\left(x-\alpha_{i}\right)+b_{0} \prod_{i=1}^{n-1}\left(x-\alpha_{i}\right)+y_{1}+ \\
& +\prod_{i=2}^{n-1}\left(x-\alpha_{i}\right) y_{2}\left(x-\alpha_{1}\right) \prod_{i=3}^{n-1}\left(x-\alpha_{i}\right)+ \\
& +\ldots+y_{j} \prod_{i=1}^{j-1}\left(x-\alpha_{i}\right) \prod_{i=j+1}^{n-1}\left(x-\alpha_{i}\right)+ \\
& \left.+\ldots+y_{n-1} \prod_{i=1}^{n-2}\left(x-\alpha_{i}\right)\right] / \prod_{i=1}^{n-2}\left(x-\alpha_{i}\right)=0 .
\end{aligned}
$$

Виконаємо групуванням коефіцієнтів при однакових степенях $x$. Прирівнюючи коефіцієнти при однакових степенях $x$ одержимо наступну систему рівнянь для визначення $y_{j}(j=1,2, \ldots, n-1)$

$$
\begin{array}{ll}
(-1)^{n-1} \alpha_{1} \alpha_{2} \ldots \alpha_{n-1}+b_{0}=a_{1} ; & L=c_{0}+c_{l} \\
(-1)^{n-2} \sum_{k=1}^{n-1} \prod_{i=1}^{k-1} \alpha_{i} \prod_{i=k+1}^{n-1} \alpha_{i}-\sum_{i=1}^{n-1} y_{i}+ & \text { і визначених } \\
+(-1)^{n-1} \alpha_{1} \alpha_{2} \ldots \alpha_{n-1} b_{0}=a_{2} ; & H_{0}^{(n)}=1, \\
(-1)^{n-3} \sum_{k=1}^{n-2} \sum_{l=k+1}^{n-2}\left(1-\delta_{k l}\right) \prod_{i=1}^{k-1} \alpha_{i} \prod_{i=k+1}^{l-1} \alpha_{i} \prod_{i=l+1}^{n-2} \alpha_{i}+ & \\
+\sum_{k=1}^{n-1} \prod_{i=1}^{k-1} \alpha_{i} \prod_{i=k+1}^{n-1} \alpha_{i} y_{k}+(-1)^{n-1} \sum_{k=1}^{n-1} \prod_{i=1}^{k-1} \alpha_{i} b_{0}=a_{3} ;
\end{array}
$$

$$
\begin{aligned}
& \sum_{i=1}^{n-1} \alpha_{i}+\sum_{k=2}^{n-1} \sum_{l=k+1}^{n-1} \alpha_{k} \alpha_{l} y_{1}+\ldots+\sum_{k=1}^{n-1} \sum_{l=k+1}^{n-1}\left(1-\delta_{i j}\right) \times \\
& \times \alpha_{k} \alpha_{l} y_{j}+\ldots+\sum_{k=1}^{n-2} \sum_{l=k+1}^{n-2} \alpha_{i} \alpha_{l} y_{n-1}=a_{n-1} ; \\
& \sum_{i=1}^{n-1} \alpha_{i} y_{1}+\ldots+\sum_{i=1}^{n-1}\left(1-\delta_{i j}\right) \alpha_{j} y_{j}+ \\
& +\ldots+\sum_{i=1}^{n-2} \alpha_{i} y_{n-1}+\sum_{i=1}^{n-1} \alpha_{i} b_{0}=a_{n} .
\end{aligned}
$$

Якщо вибрати всі $\alpha_{i}$ попарно різними, то остання система $n$ рівнянь $3 n$ невідомими $y_{i}(i=1,2, \ldots, n-1)$ матиме єдиний розв'язок. Використовуючи закон композиції (9) для $x$ одержимо наступний розклад у ГЛД

$$
x=b_{0}+\sum_{i=1}^{n-1} \frac{y_{i} \mid}{\mid b_{0}-\alpha_{i}}+. .+\sum_{m=l}^{n-1} \frac{y_{m} \mid}{b_{0}-\alpha_{m}}+.(10)
$$

Що й треба було довести.

Питання збіжності такого ГЛД до розв'язку рівняння розглядатись не буде. А питання збіжності самого дробу можна вивчити використовуючи відомі достатні ознаки [4], [6], [7].

Існує інший підхід, котрий базується на теоремі [Трон i Джоунс], яка дає необхідні i достатні умови того, що для заданого формального степеневого ряду (ФСР) існує відповідний правильний $C$-дріб. Вона також дає явні вирази для коефіцієнтів правильного Сдробу через коефіцієнти ФСР. Умови формулюються за допомогою визначників Ганкеля $H_{k}^{(n)}$ (порядку $k$ ), пов'язаних із ФСР

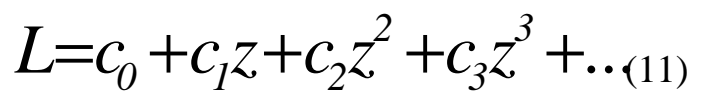

і визначених у наступний спосіб 
$H_{k}^{(n)}=\left|\begin{array}{cccc}c_{n} & c_{n+1} & \ldots & c_{n+k-1} \\ c_{n+1} & c_{n+2} & \ldots & c_{n+k} \\ \ldots & \ldots & \ldots & \ldots \\ c_{n+k-1} & c_{n+k} & \ldots & c_{n+2 k-2}\end{array}\right|$,

$k=1,2,3, \ldots$.

Теорема 2 [1].

(А) Якщо для заданого ФСР (11) існує правильний $C$-дріб

$$
1+K_{n=1}^{\infty}\left(a_{n} z / 1\right), a_{n} \neq 0
$$

який відповідає $L$ (в точці $z=0$ ), то

$$
H_{k}^{(1)} \neq 0 \text { i } H_{k}^{(2)} \neq 0, k=1,2,3, \ldots
$$

$$
\begin{aligned}
& a_{1}=H_{1}^{(1)}, a_{2 m}=-\frac{H_{m-1}^{(1)} H_{m}^{(2)}}{H_{m}^{(1)} H_{m-1}^{(2)}}, \\
& a_{2 m+1}=-\frac{H_{m+1}^{(1)} H_{m-1}^{(2)}}{H_{m}^{(1)} H_{m}^{(2)}}, m=1,2,3, \ldots
\end{aligned}
$$

(Б) Навпаки, якщо співвідношення (14) i (15) мають місце, то правильний $C$-дріб із коефіцієнтами $a_{n}$, які визначені із рівностей (14) i (15) , відповідають ряду. (11)

\section{3. РОЗВ'ЯЗАННЯ МАТРИЧНИХ ПОЛІНОМІАЛЬНИХ РІВНЯНЬ}

Мова йде про рівняння виду

$$
\sum_{i=1}^{n} A_{i} X^{n-i}=0
$$

де сталі $A_{i}$ та невідома $X-$ квадратні матриці порядку $n$.

У припущенні, що $X=0$ не є розв'язком даного рівняння на основі (16) можна записати:
$X=-\left(A_{0}+A_{1} X^{n-2}+\ldots+A_{n-2} X+A_{n-1}\right)^{-1} A_{n}$.

Застосовуючи тепер тотожність Ейлера для зв'язку між рядами і ланцюговими дробами [9], останню рівність можна подати у вигляді

$$
\begin{aligned}
& X=\frac{-A_{n} \mid}{\mid O}+\frac{A_{n-1} \mid}{\mid E}-\frac{A_{n-1}^{-1} A_{n-2} X \mid}{\mid E+A_{n-1}^{-1} A_{n-2} X}- \\
& -\frac{A_{n-2}^{-1} A_{n-3} X \mid}{\mid E+A_{n-2}^{-1} A_{n-3} X}-\ldots-\frac{A_{0}^{-1} A_{1} X \mid}{\mid E+A_{0}^{-1} A_{1} X}
\end{aligned}
$$

Використовуючи закон композиції (16) можна записати наступний розклад $X$ у нескінченний фігурний [4] гіллястий ланцюговий дріб

$$
X=\frac{\frac{-A_{n}}{A_{n-1}}}{E-\frac{\frac{-A_{n-1}^{-1} A_{n-2} A_{n}}{E-\ldots}}{E+\frac{-A_{n-1}^{-1} A_{n-2} A_{n}}{\frac{A_{0}^{-1} A_{1} A_{2}}{E-\ldots}}}}
$$

Для неформального застосування (18) у системах комп'ютерної алгебри слід застосовувати ознаки збіжності й стійкості гіллястих ланцюгових дробів.

Необхідно зазначити, що для запису розв'язків рівняння (16) гіллястими ланцюговими дробами можна також застосовувати так звані $T$-дроби та $C$-дроби [4]. Але їх опис так само як і отримання кортежів розв'язків, їх відокремлення $\epsilon$ предметом окремого дослідження.

Засобами алгоритмічної мови програмування $\mathrm{C}++$ написані процедури для розв'язання рівнянь виду (5) за допомогою розкладу в періодичний гіллястий ланцюговий дріб, а також у фігурні $T$ дроби, $J$-дроби та $C$-дроби. При розв'язанні рівняння $x^{3}-6 x^{2}+11 x-6=0$ після 12 ітерацій були одержані наступні результати.

$$
\begin{aligned}
& \left(A_{0}+A_{1} X^{n-2}+\ldots+A_{n-2} X+A_{n-1}\right) X+A_{n}=0 . \\
& \text { Звідки }
\end{aligned}
$$

\begin{tabular}{|c|c|c|c|}
\hline $\begin{array}{c}\text { Алго- } \\
\text { ритм }\end{array}$ & $\begin{array}{c}\text { Періодич- } \\
\text { ний ГЛД }\end{array}$ & $\begin{array}{c}\text { Фігурний } \\
\text { С-дріб }\end{array}$ & $\begin{array}{c}\text { Фігурний } \\
\text { Ј- дріб }\end{array}$ \\
\hline $\begin{array}{c}\text { Значення } \\
x\end{array}$ & 0,99999427 & 1,00000 & 1,0480819 \\
\hline Нев'язка & 1,14441900 & 0 & 0,0893395 \\
\hline
\end{tabular}




\section{ВИСНОВКИ}

Хоча наведені результати обчислювального експерименту виглядають досить переконливо, залишається відкритим перш за все питання збіжності алгоритму до розв'язку рівняння. Але це буде предметом вивчення в наступних публікаціях.

\section{СПИСОК ЛІТЕРАТУРИ}

1. Джоунс У., Трон В. Непрерывные дроби. Аналитическая теория и приложения. - М.: Мup, 1985, 414 c.

2. Дж. Дэвэнпорт, И. 86 Э.Турнье. Компьютерная алгебра. - М.: Мир, 1991.$352 c$.

3. В.В.Воеводин "Численные методы алгебры". -М.: Наука, 1966.

4. А.Акритас. Основы компьютерной алгебры с приложениями. - М., Мир, 1994. 544 с.

5. Д.И.Боднар. Ветвящиеся иепные дроби. - К.: Наукова думка, 1986. -176 c.

6. М.О.Недашковський, Л.П.Федунеиь. "Розв'язування систем лінійних алгебрайчних рівнянь матричними ланцюговими дробами”. - Матеріали VIII Міжнародної Наукової Конференції ім. академіка М.Кравчука, Київ -2000, c.333.

7. Н.А.Недашковский. $О$ сходимости и вычислительной устойчивости ветвящихся цепных дробей некоторых типов. Математические методы и физикоматематические поля. К.: Наукова думка, 1984, выı. 20, -c.27-31.

8. М.О.Недашковський. Елементи аналітичної теорії гіллястих ланцюгових дробів. Тези доповіді міжнародної школи-семінару “Ланиюгові дроби, ̈̈х узагальнення та застосування”, Ужгород 19-24 серпня 2002 року. Ужсгородський наиіональний університет, 2002. - с.40-43.

9. П.І.Боднарчук, В.Я.Скоробогатько. "Гіллясті ланиюгові дроби та їх застосування”. -К.: Наукова думка, 1974.

\begin{abstract}
Микола Недашковський, 1951 року народження, закінчив фракультет автоматики Львівського політехнічного інституту, за спеціальністю "Прикладна математика". У 1980 році захистив кандидатську дисертацію “Розв'язування систем лінійних алгебрайчних рівнянь гіллястими ланцюговими дробами" за спеціальністю 01.01.07 "Обчислювальна математика". У 1995 році захистив докторську дисертацію на тему "Алгоритми $і$ методи комп'ютерної алгебри для систем лінійних алгебраїчних рівнянь 3 поліноміальними елементами" за спеціальністю 01.05 .02 "Математичне моделювання і обчислювальні методи в наукових дослідженнях".

На даний час працює завідувачем кафедри автоматизованих систем i програмування Тернопільської академії народного господарства.

Наукові інтереси: комп'ютерна алгебра, паралельні обчислення, математичний аналіз, створення пакетів прикладних програм 3 комп'ютерної алгебри та системного аналізу.
\end{abstract}

